DE LA MARIPOSA A LA TORMENTA:

\title{
ANÁLISIS DE LOS COMENTARIOS DE LOS LECTORES EN LA RED A TEXTOS ARGUMENTATIVOS IRÓNICOS*
}

\section{FROM THE BUTTERFLY TO THE STORM: ANALYSIS OF THE COMMENTS OF THE READERS IN THE NETWORK TO ARGUMENTATIVE IRONIC TEXTS}

\author{
Miguel Ángel Caro Lopera \\ Universidad del Quindío, Colombia \\ Email: macaro@uniquindio.edu.co
}

Recibido: 01/07/2017

Aceptado: 05/09/2017

\begin{abstract}
Resumen
El propósito de este artículo es analizar los comentarios de los lectores en la Red sobre un texto argumentativo irónico, en contraste con los formulados a un texto argumentativo no irónico en contextos de producción similares. A pesar del número mayor de comentarios para el texto no irónico, estos se pueden agrupar en torno a las categorías de adhesión y rechazo; en cambio, para el irónico emergen múltiples respuestas que revelan toda una tormenta patética propiciada por la ironía al otro lado del lector.

PALABRAS CLAVE: Ironía verbal, columnas de opinión, comprensión lectora, análisis textual, comentarios en la Red.
\end{abstract}

\begin{abstract}
The purpose of this paper is to analyze readers' comments on the web about an ironic argumentative text, in contrast with those formulated in a non-ironic argumentative text in similar production contexts. Despite the greater number of comments for the non-ironic text, these can be grouped around the categories of adhesion and rejection; Instead, for the ironic, there emerge multiple answers that reveal an entire emotional storm caused by irony on the other side of the reader.

KEYWORDS: Verbal irony, opinion columns, reading comprehension, comments on the Web.
\end{abstract}

\footnotetext{
* Este artículo de reflexión se deriva de la tesis doctoral, actualmente en construcción, La comprensión de textos argumentativos irónicos: Hacia una didáctica de la ironía, dirigida por las doctoras Zahyra Camargo Martínez y Graciela Uribe Álvarez; tutora internacional: Dra, Leonor Ruiz-Gurillo. Doctorado en Ciencias de la Educación, Universidad del Quindío, RUDECOLOMBIA.
}

Para citar este artículo / To cite this article: Caro Lopera, Miguel Ángel (2017). De la mariposa a la tormenta: análisis de los comentarios de los lectores en la red a textos argumentativos irónicos. ELUA, 31: 97-116. doi: 10.14198/ELUA2017.31.05

Enlace / Link: http://dx.doi.org/10.14198/ELUA2017.31.05 


\title{
1. INTRODUCCIÓN
}

\author{
"Porque la ironía hace hablar. La ironía suelta las lenguas" \\ (Jankélévitch 2012: 68).
}

Con el presente trabajo pretendemos acercarnos a los efectos perlocutivos que revelan los comentarios de los lectores en la Red, alrededor de textos argumentativos irónicos ${ }^{1}$. Por tratarse de reacciones producidas en el ámbito de la comprensión lectora al contacto con textos escritos, efectuamos esta aproximación desde el modelo constructivo-integrativo (Van Dijk y Kintsch 1978 y 1983; Kintsch 1998), en concreto, desde sus niveles de código de superficie, texto base y marco situacional. En cuanto al código de superficie, se destacan los problemas de reconocimiento de relaciones notacionales, sintácticas y semánticas entre palabras clave; en cuanto al texto base, se identifican tanto la macroestructura textual como la red microestructural que la soporta; y en cuanto al marco situacional, se estudia la construcción de una imagen mental elaborada a partir de los conocimientos previos y de las inferencias ${ }^{2}$.

Este análisis surge de un corpus de 137 comentarios que aparecen en la página web de la Revista Semana (Colombia), a propósito de un texto eminentemente irónico de Daniel Samper Ospina, “iSe me van a la guerra, hijitos!”, publicado el 3 de abril de 20163. Las observaciones que de allí se desprenden las contrastamos con los 268 comentarios a un texto argumentativo no irónico de Daniel Coronell, "La criminalización del que investiga"4, publicado a la semana siguiente en la misma revista y en contra del mismo personaje, el expresidente colombiano Álvaro Uribe Vélez. Procede aquí un método hermenéutico, anclado en la búsqueda e interpretación de marcas textuales que nos lleven a la construcción de categorías, a partir de las cuales nos podamos acercar a las intenciones de los hablantes, al sentido y a las funciones de sus expresiones, así como a su valoración en contexto. Nos anima, entonces, la ruta que para el quehacer hermenéutico propone Martínez Miguélez (2004: 102): “descubrir los significados de las cosas, interpretar lo mejor posible las palabras, los escritos, los textos, los gestos y, en general, el comportamiento humano, así como cualquier acto u obra suya, pero conservando su singularidad en el contexto de que forma parte".

Tal elección supone ciertas restricciones, como la imposibilidad de emitir juicios fiables sobre niveles de comprensión de lectura, pues el comentario de textos, concebido por la revista misma como espacio de participación no puede pensarse, en ningún momento, como examen de comprensión lectora; de ahí que los alcances de nuestros propósitos no rebasen la descripción los efectos perlocutivos de las columnas de opinión en quienes libremente compartieron, a través de la Red, sus opiniones al respecto. En este orden de ideas, nos adherimos a las observaciones de Magdaleno y Gutiérrez-Rivas sobre las bienhadadas po-

\footnotetext{
1 Expreso mi agradecimiento a los evaluadores anónimos asignados por la revista, ya que, gracias a su lectura cuidadosa, cualificaron con sus observaciones el contenido de este artículo.

2 Entre otras cosas, quizás, la ironía sea uno de los mejores escenarios para ilustrar el funcionamiento de este modelo, pues, en razón de la propuesta polifónica de Ducrot (1988), son bien distintas las primeras construcciones del texto-base con respecto a los resultados finales del marco situacional.

3 Disponible en http://www.semana.com/opinion/articulo/daniel-samper-ospina-hijos-de-uribe-se-alistan-parair-a-la-guerra/467619

4 Disponible en http://www.semana.com/opinion/articulo/daniel-coronell-vinculos-de-familia-uribe-conparamilitares-y-narcotrafico/468598
} 
sibilidades de Internet como "punto de encuentro con otro(s) en un tiempo y en un espacio virtual, para poder compartir información, comentar la vida, permitirse sentir, en síntesis, interactuar" (2013: 20).

Entre los antecedentes investigativos cercanos reconocemos, al menos cuatro trabajos: El primero, de Victoria Crespo-Lajara, "Las claves argumentativas de la ironía: Una aproximación argumentativa al fenómeno irónico" (2008), cuyo propósito es abordar la ironía desde la perspectiva de la teoría de la argumentación en un corpus de 57 textos periodísticos de opinión de diversa categoría, bajo el distintivo de la argumentación política. El segundo proviene del estudio que el grupo GRIALE de la Universidad de Alicante promovió sobre humor, ironía y géneros textuales (Alvarado-Ortega y Ruiz-Gurillo, coords., 2013); allí aparece el capítulo "La ironía, entre polifonía y mención ecoica: Cuando se opina en la red", en el que Pano-Alamán describe "los mecanismos de mención ecoica y de desdoblamiento de

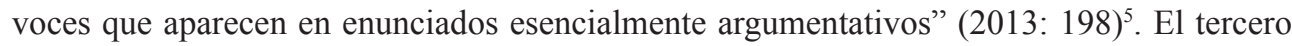
tiene que ver con el artículo "Funciones pragmáticas de la petición en los comentarios del público a una noticia periodística virtual”, en el que Magdaleno y Gutiérrez-Rivas (2013), se ocupan de 831 comentarios derivados de una noticia, también de tintes políticos, publicada en un portal web venezolano en febrero de 2011. El cuarto corresponde al de José Joaquín Martínez-Egido, "El humor en el artículo de opinión" (2014), en el que se ocupa de este fenómeno en 80 columnas de opinión publicadas en la prensa española ${ }^{6}$. De estos proyectos, solo el segundo identifica la ironía como factor derivado de los resultados, mientras que los demás la examinan como núcleo central, a la luz del modelo neogriceano que propone el ya mencionado grupo GRIALE (Ruiz-Gurillo y Padilla-García, eds., 2009).

En este intento, nos proponemos desarrollar el siguiente derrotero. En un primer momento, para sentar las diferencias entre los dos textos, los avistaremos en cuanto a su arquitectura textual, desde los presupuestos teóricos del interaccionismo socio-discursivo (Bronckart 2004). Posteriormente, como fruto de la revisión de los comentarios, ofrecemos siete categorías de análisis que pueden sustentar la tesis por la que apostamos: la irrupción, al estilo de un efecto mariposa, de una tormenta patética en el mundo de los lectores, al contacto con un texto argumentativo de ironía continuada; lo que equivale a decir, con Jankélévitch, que "la ironía hace hablar. La ironía suelta las lenguas" (2012: 68). Por último, bosquejaremos algunas conclusiones y prospecciones.

\section{UNA MIRADA A LA ARQUITECTURA TEXTUAL DE LAS DOS COLUMNAS ANALIZADAS}

En el proyecto de tesis doctoral que arropa a este texto, hablar de las arquitecturas textuales de las columnas de opinión - desde el legado del interaccionismo socio-discursivosupone un esfuerzo por avistar la complejidad de los textos, tanto en los discursos que los definen, como en los mecanismos que los tejen y en las voces que los enuncian. Esta arquitectura, expresión de lo que Bronckart considera como un milhojas textual, comprende tres niveles: la infraestructura textual, los mecanismos de textualización y los mecanismos

5 El corpus lo constituyen 644 comentarios emitidos por lectores sobre tres noticias de la versión digital de El País, entre 2009 y 2011.

6 Los artículos provienen de los tres últimos meses del 2013; 38 fueron escritos por mujeres (Rosa Montero, Elvira Lindo y Carmen Rigalt) y 42 por hombres (Juan José Millás, Ignacio Escolar y Moncho Alpuente). 
de asunción del compromiso enunciativo. El primero comprende el nivel más profundo, "constituido por el plan general del texto, por los tipos de discurso que comporta, por las modalidades de articulación de esos tipos de discurso y por las secuencias que eventualmente aparecen en él" (Bronckart 2004: 76). Para el segundo nivel, define Bronckart los mecanismos de textualización como series isotópicas que contribuyen a establecer la coherencia temática. Estos "son parte fundamental de la articulación lineal del texto y explicitan ante los destinatarios las grandes articulaciones jerárquicas, lógicas y/o temporales” (2004: 77). El último nivel está compuesto por los mecanismos de asunción de responsabilidad enunciativa, los cuales suponen la revisión de las voces y las modalizaciones que asumen el peso enunciativo de lo que dice el texto; para el caso de las columnas de opinión aquí comparadas nos interesan de modo especial las voces, desde las cuáles se clarifican las responsabilidades enunciativas, a partir de preguntas como: “¿cuáles son las instancias que asumen lo enunciado en el texto?, ¿qué voces se expresan en él?" (Bronckart 2004: 82).

Esbozaremos, a continuación, los rasgos más importantes de las arquitecturas textuales de los dos textos que entran en juego para nuestra investigación.

\subsection{La arquitectura textual en La criminalización del que investiga (Daniel Coronell)}

De esta columna, que no podríamos identificar como irónica ${ }^{7}$, sucintamente podríamos decir lo siguiente:

- En cuanto a la infraestructura textual, apreciamos la dispositio propia del discurso argumentativo, con un paratexto inicial que cumple función de exordio, así: «El señor expresidente Uribe sabe que no tiene que explicar nada, solo contraatacar con una calumnia, dejando al aire una sospecha y cambiando la agenda para que sea el investigador el que quede en el banquillo». Luego viene una narratio muy breve -según los cánones ${ }^{8}$ - gracias a la cual el autor contextualiza a los lectores sobre el asunto central: «La más reciente víctima de la estrategia es el columnista de El Espectador Yohir Akerman». Posteriormente, emerge una argumentatio dotada de pruebas extraartísticas dispuestas en orden nestoriano ${ }^{9}$, en claro movimiento tema-rema. Al final, despunta una peroratio abierta que se anticipa a las respuestas del expresidente y que anuncia la continuidad de un círculo vicioso, en el que se probará una vez más la tesis del título: la criminalización del que investiga: «Así es que ustedes ya saben lo que viene después de esta columna».

7 A lo sumo, podríamos detectar en él unas pocas ironías focalizadas, como aquella que se enmarca en la oración “iQué visión la de don Fabio!”, con la que el autor evalúa las declaraciones de Fabio Ochoa, narcotraficante colombiano, según las cuales "Alvarito", hijo de Alberto Uribe Sierra, sería futuro presidente de Colombia.

8 La narratio es la "exposición de los hechos que constituyen la causa, con el fin de que el receptor tenga un conocimiento de los mismos, que haga posible que llegue a situarse de parte de la posición defendida por el orador, ya que la narración de los acontecimientos es indispensable para que la argumentación a propósito de los mismos se lleve a cabo" (Albaladejo 1989: 86). Esta parte, eminentemente inscrita en la línea lógica, debe ser breve, clara y verosímil. 9 Dice Aristóteles: "De entre los argumentos retóricos, unos están fuera del arte y otros en él. Llamo extraartísticos todos los que no son hallados por nosotros, antes preexisten, cuales son los testigos, confesiones bajo tortura, documentos escritos y otros semejantes; artísticos, en cambio, cuantos por el método y por nosotros pueden ser dispuestos; de manera que conviene hacer uso de aquellos e inventar estos" (Retórica, §2). En cuanto al orden nestoriano, nos referimos a la disposición de argumentos, según la Retórica Antigua, que guarda para el final los más fuertes, luego de haber resguardado en el medio los más débiles (Torres-Hernández y Velandia-Pedraza 2008: 124) 
- En cuanto a los mecanismos de textualización, se resaltan tanto la cohesión nominal por valoración, como la cohesión verbal oscilante entre el pasado y el presente, todo esto en el marco de una estilística sencilla y directa, con preeminencia de oraciones compuestas, empaquetadas en párrafos cortos, tejidos por diversos conectores de enumeración para enlazar las múltiples razones que soportan la tesis, en un afán por argumentar desde la cantidad.

- En cuanto a los mecanismos de asunción del compromiso enunciativo, claramente advertimos la función locutor en quien se suscribe como autor del texto. En efecto, Daniel Coronell funge como responsable textual de su tesis y de cada uno de los argumentos que esgrime, así en su columna no aparezca en ningún momento la enunciación en primera persona del singular y prefiera, más bien, las voces impersonales.

En última instancia, podríamos comprobar, con Van Dijk, la presencia de una retórica de la facticidad, propia del género periodístico en el que se inscribe esta columna; al fin y al cabo, "los periódicos tratarán de ofrecer cuantos números precisos les sea posible, con el fin de sugerir o probar que sus noticias son fácticamente correctas (incluso a pesar de que los números sean con frecuencia pura especulación y que varíen de un periódico a otro)" (1978: 72).

\subsection{La arquitectura textual en ¡Se me van a la guerra, hijitos! (Daniel Samper Ospina)}

Sobre este texto de típica ironía continuada ${ }^{10}$, podríamos apuntar algunas observaciones:

- En cuanto a su infraestructura, el artículo se despliega como un texto argumentativo de superestructura travestida, pues, al contrario de lo que podría esperar el lector, rehúye las condiciones formales y estructurales propias del discurso argumentativo y, más bien, presenta un diálogo ficticio entre el expresidente Uribe y sus hijos, en una condición hipotética extrema: la guerra que podrían despertar sus saboteos al proceso de paz colombiano. Ante un texto que respeta todos los rasgos propios de una conversación, las inferencias superestructurales que propicia la ironía llevarían al lector a colegir todo un aparataje argumentativo. Esta práctica se inscribe en un fenómeno más amplio de hibridaciones textuales, en el que la ironía se comporta como caballo de Troya que mimetiza formas y estructuras de géneros - distintos de la columna de opinión clásica- en función de una intención carnavalesca ${ }^{11}$.

10 Con esto nos referimos, basados en GRIALE, a aquella ironía que "no aparece necesariamente en un enunciado concreto, sino a lo largo de todo un texto", para lo cual no siempre se vale de indicadores lingüísticos (RuizGurrillo et alii 2004: 237).

11 Este fenómeno se trata, de modo más extenso, en el artículo "La arquitectura textual del carnaval en las columnas irónicas de Daniel Samper Ospina” (Caro, Camargo y Uribe, en prensa). Por ahora cabe aclarar que este fenómeno no es exclusivo de Samper Ospina. Algo similar habían identificado Caro y Castrillón como uno de los procedimientos irónicos preferidos por el grupo Les Luthiers, recurso que se caracteriza por "quiebres estilísticos, permutaciones abruptas entre tipologías, inversiones enunciativas y cambios de tonalidad" (2011: 14). Allí los autores describieron diversos travestimientos textuales presentes en el discurso verbal del grupo argentino, gracias a los cuales la ironía juega con los límites borrosos de las tipologías textuales y los géneros discursivos. Así, por ejemplo, una plegaria se volvía conversación ("Los milagros de San Dádivo", 2005), un bolero se convertía en pregón político ("Serenata tímida", 1986) o un motete se transfiguraba en ronda infantil ("Somos adolescentes, mi pequeña”, 1998). 
- En cuanto a los mecanismos de textualización -y dado el carácter irónico del texto- afloran todo tipo de inversiones a los principios neogriceanos de Levinson, tal como lo ha postulado el grupo GRIALE de la Universidad de Alicante (RuizGurillo et alii 2004; Rodríguez-Rosique 2009; Ruiz-Gurillo 2012); de hecho, el principio que más se compromete en este texto es el de manera, gracias a la inserción permanente de variantes diatópicas y usos dialectales (como las paragoges y apócopes propios de la región antioqueña) con los que Samper Ospina caricaturiza al expresidente; sin embargo, también se invierte el principio de informatividad, ante el juego permanente con los dobles sentidos, propiciados fundamentalmente por la antanaclasis («avión», «culebrita», «minas», «apóstoles», «mano», todos ellos inferibles a la luz de los contextos lingüísticos y socioculturales); le sigue, aunque en menor proporción, el principio de cantidad, en virtud, fundamentalmente, de algunos sufijos («hijitos», «articulito»...). A esto se añade el recurso de la isotopía, muy cara a la oralidad, que en este caso se aplica en gradación creciente a las armas que el expresidente les va legando a sus hijos como herencia previa de sus familiares, al calor de la conversación (un fusil $<$ un revólver $<$ galil $<$ una miniuzi $<$ un misil).

- En cuanto a los mecanismos de asunción del compromiso enunciativo, advertimos un bien logrado enmascaramiento de la función locutor. Con el siguiente enunciado programático, a partir del cual el autor introduce su texto, se da paso a todo un carnaval enunciativo, en el que intervienen las voces de enunciadores absurdos (en este caso, Álvaro Uribe y sus hijos), en el marco de un diálogo ficticio: «Para que no se diga que Álvaro Uribe sabotea el proceso de paz para promover una guerra hecha con hijos ajenos, me anticipo con este diálogo que se presentará en cualquier momento del año: solo es tener paciencia». Este artilugio irónico, que se corresponde plenamente con las explicaciones de Ducrot (1988), sin duda, hace más complejo el proceso de comprensión, en términos de la relación entre sujeto empírico (Samper Ospina), locutor (como responsable de lo que se dice) y enunciadores (todos ellos absurdos) detrás de las voces que suenan en el texto.

Sobre esto último, recordemos que Ducrot califica de humorístico al enunciado que cumpla con las tres condiciones siguientes:

a. Entre los puntos de vista representados en el enunciado, por lo menos, hay uno que obviamente es absurdo, insostenible (en sí mismo o en el contexto); b. El punto de vista absurdo no es atribuido al locutor; c. En el enunciado no se expresa ningún punto de vista opuesto al punto de vista absurdo (no es rectificado por ningún enunciador) (1988: 20).

Dentro de los enunciados humorísticos -agrega más adelante Ducrot- se califican de irónicos "aquellos en que el punto de vista absurdo es atribuido a un personaje determinado, que se busca ridiculizar” (1988: 21).

En suma, la presencia de una arquitectura textual tan carnavalizada subvierte por completo tanto la retórica de la facticidad que, para un género de corte periodístico como este, ya preconizaba Van Dijk, como la máxima de cualidad -"diga la verdad"- de la que se ocupa el modelo neogriceano para la ironía del grupo GRIALE. 
El siguiente cuadro recoge las principales diferencias entre los textos, a la luz de lo explicado hasta el momento:

\begin{tabular}{|c|l|l|}
\hline \multicolumn{1}{|c|}{$\begin{array}{c}\text { La criminalización del que investiga } \\
\text { enunciativa }\end{array}$} & $\begin{array}{l}\text { iSe me van a la guerra, hijitos! } \\
\text { Textualización } \\
\text { Responsable de su voz }\end{array}$ & $\begin{array}{l}\text { Autor no locutor de su texto } \\
\text { Elección irónica de la víctima como } \\
\text { narrador del texto }\end{array}$ \\
\hline $\begin{array}{l}\text { Enumeración de argumentos con } \\
\text { ligaduras sintácticas de que anunciativo } \\
\text { Retórica de la facticidad } \\
\text { Estilística sencilla y directa } \\
\text { Movimiento tema } \text { rema } \text { desde } \\
\text { evidenciales }\end{array}$ & $\begin{array}{l}\text { Ironía continuada con inversión de los } \\
\text { principios de Levinson (GRIALE) } \\
\text { Isotopía en gradación del legado de } \\
\text { armas } \\
\text { Variantes diatópicas y usos dialectales } \\
\text { Dobles sentidos irónicos contextuales }\end{array}$ \\
\hline Infraestructural & $\begin{array}{l}\text { Texto argumentativo con dispositio } \\
\text { clásica: } \\
\text { Paratexto inicial con función de } \text { exordio } \\
\text { Narratio breve } \\
\text { Argumentatio con pruebas extra- } \\
\text { artísticas en orden nestoriano } \\
\text { Peroratio abierta }\end{array}$ & $\begin{array}{l}\text { Texto argumentativo con } \\
\text { superestructura travestida: } \\
\text { Primicia de un diálogo "que se dará" } \\
\text { entre el expresidente Uribe y sus hijos } \\
\text { durante la guerra que despertarán sus } \\
\text { saboteos al proceso de paz }\end{array}$ \\
\hline \multicolumn{2}{|l}{} \\
\hline
\end{tabular}

Tabla 1. Comparación entre arquitecturas textuales de las columnas revisadas.

A partir de lo anterior y a modo de conjetura inicial, podríamos afirmar que estas diferencias profundas entre los textos aquí descritos (uno ligado tan claramente a los cánones del género, y otro tan alejado de ellos) pueden arrojar diferentes efectos perlocutivos en los lectores. Verificar esa conjetura será el propósito del siguiente apartado.

\section{RESULTADOS DEL ANÁLISIS}

Luego de haber perfilado las arquitecturas textuales de las dos columnas de opinión, presentamos, a continuación, las principales categorías de análisis que emergen de la lectura de los comentarios de los lectores en la Red: 268 para el texto de Daniel Coronell (DC) y 137 para el de Daniel Samper Ospina (DSO) ${ }^{12}$. Se trata de siete categorías, de las cuales las dos primeras parten de indagaciones cuantitativas, mientras que las cinco restantes salen de la detección de algunos comentarios representativos, a los que luego se adosaron ciertas recurrencias, todo esto en el marco de una postura hermenéutica que -según Moreno Fernández- reconoce los datos individuales como "significativos por derecho propio, al margen de que admitan ser organizados en escalas o agrupaciones de índole diversa” (1990: 110).

12 Los números de esta muestra resultaron de un proceso de depuración previa que supuso la eliminación de: 1. Comentarios repetidos; 2. Comentarios no pertinentes relacionados con campañas publicitarias u ofrecimiento de bienes y servicios; 3. Comentarios como respuesta a otros comentarios (pues en este caso, el asunto, más que ubicado en el texto mismo, se cierne sobre el comentario del otro lector). Este último fenómeno discursivo ya había sido descrito por Pano-Alamán como "discurso doble en el que un participante se dirige a todos y dialoga con algunos" (2013: 201); de ahí que lo hayamos omitido, al menos, para este trabajo. 


\subsection{Adhesión, rechazo e indefinición de los comentarios}

La primera búsqueda que emprendimos a lo largo del corpus tenía que ver con la adhesión y rechazo de los lectores a la propuesta argumentativa de los dos textos, ya que estos, de entrada, se clasificaban por la revista misma en la sección de columnas de opinión. El siguiente gráfico da cuenta de los resultados:

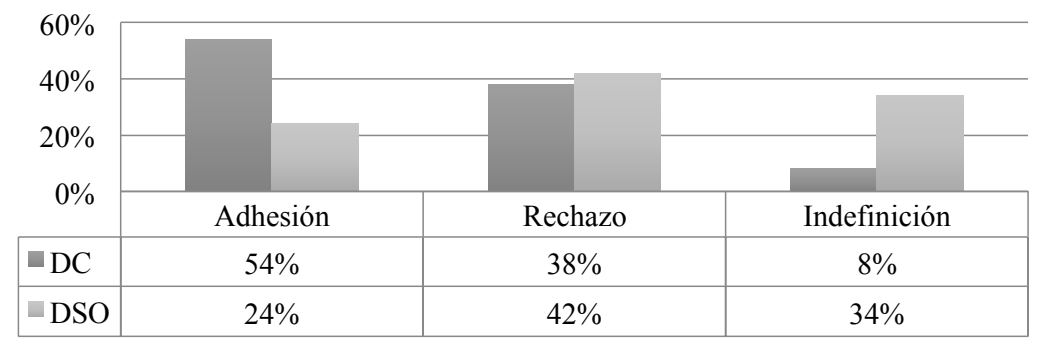

Gráfico 1. Resultados en cuanto a adhesión, rechazo e indefinición.

En este caso, más allá de ocuparnos de los niveles de adhesión o de rechazo que hayan suscitado los artículos, nos interesa detenernos en los márgenes de la indefinición, pues, a menores porcentajes de ella, resulta mayor la efectividad persuasiva a la que aspira un texto argumentativo. Precisamente, eso es lo que consigue el artículo no irónico con un 8\%: independiente de que los lectores estén de acuerdo o en desacuerdo, importa que, al menos, hayan tomado una postura. En cambio, el 34\% de comentarios que, para el texto irónico, no expresan claramente la adhesión o rechazo, arroja un manto de duda razonable sobre la comprensión que los lectores lograron del mismo. Esto le da la razón a Arrieta, quien afirma que existe mayor dificultad para comprender la ironía continuada, en virtud de la activación de inferencias para capturar el sentido global del texto, sobre todo en aquellos casos -como el del texto de Samper Ospina- que se alejan de lo que la autora considera como una comunicación seria o literal (2013: 640) ${ }^{13}$.

\subsection{Origen de los argumentos: Intratextuales, extratextuales y no pertinentes}

Una mirada más cuidadosa a los comentarios buscó establecer de dónde provenían los argumentos que empleaban los lectores para sustentar sus juicios. Así, registramos comentarios cuyos argumentos procedían directamente del texto al que se referían, bien fuera para la ampliación, la rectificación, la identificación, la negación o la controversia (intratextuales).

13 Se trata de una investigación diagnóstica sobre la comprensión de textos argumentativos en la Universidad de Cartagena (Colombia) a una población de 1117 estudiantes de 22 programas académicos, llevada a cabo durante los años 2012 y 2013. Entre los referentes teóricos del proyecto, declara, por un lado, la perspectiva discursiva del lenguaje de Charaudeau y Martínez, quienes, a su vez, se basan en Bajtín y Ducrot, ante todo en las temáticas relacionadas con la polifonía en la argumentación y las inferencias enunciativas; y por otro, los aportes del grupo GRIALE, en cuanto a ironía focalizada y continuada. Los dos textos, a partir de los cuales se estructuran los instrumentos de medición, se inscriben en estos tipos de ironía; el primero -"El aborto y la moral" de Héctor Abad Faciolince con 20 preguntas- registra ironías focalizadas, mientras que el segundo -"El Joe: un negro menos" de Godofredo Cínico Caspa con 10 preguntas- se constituye en ejemplo clásico de ironía continuada. 
Por el contrario, otros comentarios incluían ideas que no se debatían en el texto central (extratextuales), mientras que otros más incorporaban elementos temáticos por completo ajenos a la discusión (no pertinentes). El panorama se resume en el siguiente gráfico:

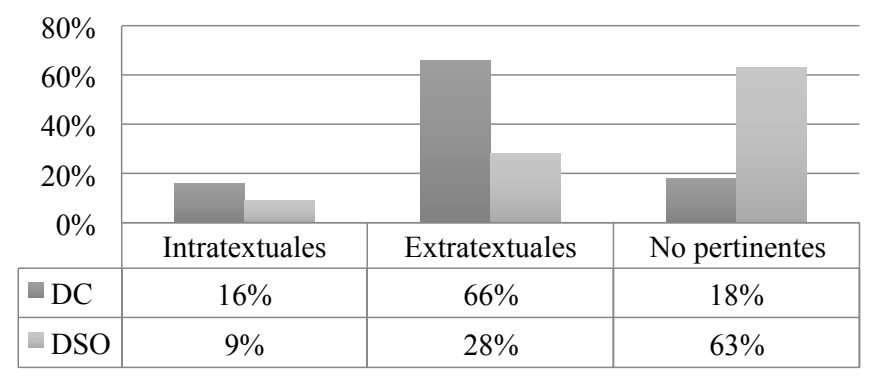

Gráfico 2. Resultados en cuanto al origen de los argumentos.

Como podemos notar, para el texto no irónico (DC), el exiguo porcentaje de argumentos intratextuales (16\%), en contraste con el $66 \%$ de extratextuales, deja al desnudo la sentencia de Nielsen de que los usuarios de la Red no leen: "solo hojean" (2000: 106-111). Todo esto, en términos del modelo constructivo-integrativo (Van Dijk y Kintsch 1978 y 1983; Kintsch 1998), devela una lectura que evade las construcciones a partir del texto base, mientras que se aferra a los dictámenes apriorísticos de un incipiente marco situacional que aún no alcanza la integración de las imágenes mentales; se erige, entonces, la presencia de un lector que opina sobre el texto sin leerlo, solo guiado por sus saberes previos y sus prejuicios, máxime si en este caso se ponen en juego las preferencias políticas y los imaginarios sociales al respecto. Para el texto irónico (DSO), la situación persiste, tal como lo notamos en quienes afianzan sus posiciones con argumentos intratextuales (9\%); sin embargo, el fenómeno rebasa la situación del texto no irónico, pues al $28 \%$ de quienes echan mano de argumentos extratextuales, se impone un aplastante $63 \%$ constituido por quienes repuntan con razones que no vienen al caso. Aquí la hipótesis de Nielsen es llevada al extremo, patrocinada por un texto irónico que se lee sin leer y que se juzga tras el prisma de los amores y los odios, las representaciones sociales y las experiencias del pasado, signadas por dos siglos de pugnas políticas en el marco de una convulsiva democracia.

\subsection{Un código de superficie provocador: ¡A la guerra, hijitos!}

De acuerdo con el modelo constructivo-integrativo antes reseñado, el código de superficie se constituye en uno de los niveles de representación que, junto con el texto base y el modelo situacional, permiten explicar el proceso a través del cual una persona comprende textos orales y escritos. En medio de las dinámicas interactivas entre el mundo del lector y el mundo del texto, el código de superficie se ocupa, como su nombre lo sugiere, del procesamiento perceptivo de las primeras capas de las palabras y las oraciones ${ }^{14}$. Al

14 El código de superficie tiene que ver con "una representación lingüística superficial que se elabora, a partir de las palabras incluidas en el texto y de otros elementos constituyentes de la oración" (Camargo, Uribe y Caro 2011: 167). 
respecto, Van Dijk y Kintsch anotan la profunda simbiosis de estos niveles de representación, al servicio de la producción y la comprensión de los textos: "Language users always manipulate surface structures, word, phrase, and clause meanings, pragmatic information from the context, as well as interactional, social, and cultural data" (1983: 78).

En los comentarios al texto irónico, emerge, en este sentido, un fenómeno curioso: Algunos lectores supeditan por completo su reacción al código de superficie que se advierte en el título «iA la guerra, hijitos!» y responden apasionados a lo que creen como macroestructura del texto. Miremos varios de ellos ${ }^{15}$ :

- Buen artículo porque es la verdad: los hijos de los ricos, los fanáticos seguidores de este mesías narcotraficante y creador de los paramilitares no pelean esta guerra. Son los hijos del pueblo y los asesinan porque la vida para ellos no vale: falsos positivos (Hernando Pérez)

- Este artículo es la realidad, la sangre de los colombianos más pobres es la que se derrama en esta guerra de 60 años, solo por tener el dominio de la tierra en un puñado de hombres ambiciosos como Álvaro Uribe y sus amiguis (Gilbercar@hotmail.com)

- El h.p. Uribe pensará que le voy a prestar mis hijos para la guerra: primero lo llevo a una corte internacional pero jamás permitiré mis hijos en ese ejército (Mefistófeles)

En estos casos, si recuperamos la metáfora del comienzo, el aleteo de una mariposa en el título, en virtud de la provocación de su código de superficie, desencadena auténticas tormentas perlocutivas, estimuladas por el temor que genera el cruce de dos mundos semánticos tan poderosos y antitéticos como la guerra y los hijos. Esto no solo le da la razón a la sentencia de Nielsen antes citada, sino también a otras hipótesis que navegan en sentido parecido, como la preeminencia de la estrategia skim, a la hora de leer textos en la Red, según Cassany, Luna y Sanz (2003: 199-200); sin duda alguna, los comentarios anteriores son hijos del skimming, del vistazo a la página, del paso veloz por los tags, de las conjeturas apriorísticas al contacto con un título que porta una palabra tan atemorizante como la guerra. Aquí, ante la irrupción del principio pragmático del atisbo y opino, la ironía nos permite recoger interesantes perlocuciones auspiciadas por la respuesta primigenia de un cerebro que se siente atacado, de un lector que responde reptílico al peligro de perder a sus hijos en combate; de un cazador de skimmings que reacciona asustado ante el monstruo de la guerra sin percatarse, acaso, de que simplemente en el título, oculta detrás de un código de superficie, aletea la mariposa de un inofensivo enunciador absurdo.

\subsection{La descarga perlocutiva del elogio directo}

En un espacio discursivo como el del comentario en la Red que facilita las reacciones espontáneas, el elogio directo se constituye en la expresión por excelencia de la adhesión persuasiva. El corpus revisado no podría ser la excepción; sin embargo, alcanzamos a percibir una mayor presencia del fenómeno en los comentarios al texto irónico, así:

15 En la transcripción de los comentarios solo introdujimos correcciones ortotipográficas para evitar al lector distracciones por ese tipo de erratas. Lo demás es fiel a las fuentes. 


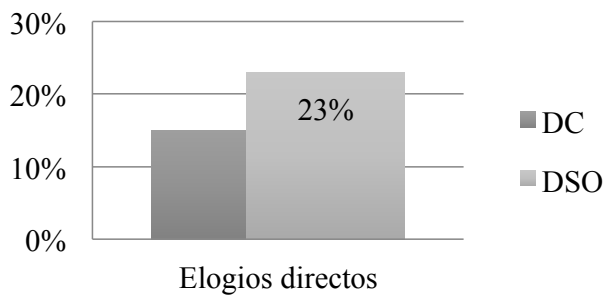

Gráfico 3. Resultados en cuanto a la presencia de elogios directos.

Aunque en términos porcentuales la distancia parece poca, en términos cualitativos la exaltación de los comentarios al texto irónico es evidente. Podríamos afirmar que, en el texto no irónico, la discusión centrada en los argumentos inclina los comentarios hacia el acuerdo o el desacuerdo, mientras que en el texto irónico los remite, más bien, hacia el gusto o el disgusto. Incluimos, en esta categoría los elogios más resonantes:

[1] Excelente como siempre. Humor comparado solamente con el gran Jaime Garzón (Mona 48)

[2] No sé si te importe, pero te amo, igual que a tu apá jajajaja $\left(\mathrm{EC}^{1}\right)$

[3] Genial, carajo (Olegario)

[4] Felicitaciones, me gustó mucho el sarcasmo... Mejor imposible (Facundo)

[5] Gracias a las risas que nos provocas mitigamos la tristeza, el asco, las náuseas, la rabia que nos provocan estos cínicos mentirosos, marrulleros, desfachatados del poder gas (AB)

[6] Brutal la columna como todas las de Samper. Esa sátira sí que sirve para este pueblo apelotargado de tanta corrupción, inmoralidad y muerte (Pedro Peluchín)

[7] Genial, sencillamente genial la forma en que usted con excelente humor describe esta situación que nadie se atrevía a expresar (Santasanti)

[8] La verdad siempre es buena, sin importar el estilo que se maneje para decirla!!! Felicitaciones!!! Excelente artículo (Yo opino)

[9] Excelente, gracias a periodistas como usted es que nos salvamos del cinismo descarado. Más clara la verdad no puede quedar $\left(\mathrm{ZM}^{2}\right)$

En esta muestra, el reconocimiento intuitivo que los lectores hacen de conceptos como el humor, el sarcasmo y la sátira nos hacen pensar en una ironía continuada que ha dado en el blanco perlocutivo: provocar risa y, a la vez, la reflexión. Si tenemos en cuenta las tres funciones principales de la ironía, según Alba-Juez (2002: 558) - evaluación, ataque verbal $y$ diversión-, la detección que hacen los lectores de la función evaluativa se nota claramente en [5], [6], [7], [8] y [9]; la complacencia por los ataques verbales se aprecia, con marcado énfasis, en los comentarios [4], [5], [6] y [9]; mientras que la ponderación de lo divertido se evidencia en [1], [2], [3], [5] y [7]. Así las cosas, para un texto de ironía continuada, el elogio directo parece convertirse en la deseada presea perlocutiva, pues -a diferencia de los textos no irónicos- a la denuncia, la reflexión, el ataque, la crítica..., se añade el ingrediente inesperado de la risa. Tampoco podríamos soslayar la importancia que reviste el hecho

16 En vista de que algunos lectores suscribieron su nombre completo, por respeto a su identidad, solo anotamos aquí sus iniciales.

17 Del mismo modo, como algunos lectores incluyeron su correo electrónico, solo registramos sus iniciales. 
de alcanzar este tipo de comprensiones alrededor de un texto de arquitectura textual tan carnavalizada, según lo habíamos anotado antes. Sin duda, inferir al tiempo evaluaciones, ataques y diversión en medio de un texto que renuncia a la dispositio argumentativa clásica y se camufla en las formas del diálogo, que juega con los principios conversacionales, que invierte la máxima de la cualidad, que socava la retórica de los hechos y que introduce toda suerte de enunciadores absurdos, es tarea compleja. No en vano, en el marco de las buenas prácticas argumentativas, Vega-Reñón reconoce los poderes de lo implícito y con ello señala una labor imponderable de lectura: el desafío de un lector capaz de comprender "el poder subversivo de ciertas relaciones entre lo dado a entender y lo dicho, [sobre las cuales] despliega su potencia la ironía" (2007: 74).

Por otra parte, el contacto emocional que privilegian estos lectores con el autor del texto nos recuerda a Yus, quien postula la actitud afectiva (affective attitude) como elemento imprescindible para que el interlocutor identifique no solo la actitud disociativa del hablante, sino también sus sentimientos o emociones hacia la opinión, la norma o el enunciado que la ironía ecoíza: "what is at stake in the relationship between irony and humour is the hearer's ability to identify not only the speaker's dissociative attitude, but also his feelings or emotions towards the opinion, norm, or utterance that the irony echoes" (2016: 220). Esta actitud afectiva, en sus más diversas expresiones, revela también su presencia en las categorías que desglosamos a continuación.

\subsection{La tormenta de la falacia $A d$ hominem}

Otra situación de magnitud porcentual muy similar a la anterior despunta en el corpus revisado. Tiene que ver con la presencia de la falacia ad hominem, considerada por BordesSolanas como "una de las formas más habituales de intento vano por refutar los argumentos del adversario en una discusión crítica" (2011: 201). La misma autora la describe como una forma de ataque "a la persona que formula el argumento (ad personam) en lugar de atacar el argumento mismo (ad rem) y pasarle así la carga de la prueba” (2011: 201). Este es el reporte estadístico al respecto:



Gráfico 4. Resultados en cuanto a presencia de falacias.

Ya en terrenos cualitativos -y en concreto para el texto irónico- registramos una importante tendencia de comentarios hacia el ad hominem circunstancial, catalogado por BordesSolanas como desprestigiar al adversario "remitiendo a las circunstancias que le rodean, relativas a su trabajo, familia o nacionalidad" (2011: 207); por ejemplo: 
- Daniel Samper, debería tener algo de vergüenza. Usted antes de difamar a los demás primero debería verse a un espejo. El espejo de la vergonzosa familia a la que pertenece, la de su tío Ernesto y su padre... (JC.Kings)

- Este señor por qué no averigua la corrupción del tío el Bojote, de Serpa y los asesinatos que orquestaron mientras que estaban unidos con los narcos durante la peor presidencia de la historia de Colombia. El tío de este señor institucionalizó la delincuencia en la presidencia. Por esto, estamos sin justicia en Colombia (Cenicienta336)

- El que tiene rabo de paja no se arrime a la candela, por qué mejor no escribe sobre el lujo de tío que tiene y la relación con los angelitos de Unasur (ERQ)

- Cómo le dan cabida a un pseudoperiodista que se las tilda de chistoso, cuando solo es un mamarracho al servicio de la oligarquía. Por qué no se dedica a publicar todos los enredos del mafioso ñoño de su tío Ernesto Samper, que nunca entregó el poder después que todo el país sabe de los vínculos con los narcotraficantes de Cali; llegó al poder con ese billete ensangrentado y mafioso. Usted como familia también debe haberse lucrado de ese dinero sucio y ahora se las tilda de honesto y de escritor chistoso (Jachimin)

La recurrencia en las ofensas a Samper Ospina por ser el sobrino del expresidente Samper Pizano ya ha sido registrada por la investigación; Cortés-Martínez, por ejemplo, luego de analizar la argumentación, las falacias y la participación de las audiencias de las columnas de opinión de 6 periodistas colombianos ${ }^{18}$, asevera, en referencia a Samper Ospina: "Muchos lectores no le perdonan ese nexo. La sombra del monumental elefante del 8.000 también se adueñó del foro del columnista. [...] Los lectores cometen falacia ad hominen ofensiva por la circunstancia (por cobrarle su parentesco con el exmandatario)" (2010: 195).

\subsection{La profusión del insulto directo}

Desde la tercera categoría de este análisis, los datos han dibujado las más diversas reacciones de los lectores en la línea del pathos: el temor instintivo a perder los hijos en la guerra, los más cálidos elogios al columnista y los argumentos pasionales atizados por sus circunstancias familiares; de la mano de tales reacciones, irrumpe también la del insulto directo, como en los siguientes casos:

[1] La verdad a este tipo tan ridículo da asco leerlo, prestarle cinco de atención. ¿Entonces qué vas a hacer tú por la patria? ¿Tú tienes los huevos bien puestos acaso? ¿O más bien tu Santos te unta de mermelada y te cierra la boca para que escribas a su favor? Tú eres una simple y llanamente una sola persona, una sola mente y muy escasa que piensa así. Acá somos más de 30 millones de colombianos que no queremos esta paz llena de vicios ocultos, de lavado de activos, de narcoterrorismo, de impunidad, de ocultismo, de socialismo. Esta paz de mentiras que solo es para que los que la apoyan se enriquezcan con los dineros mal habidos, manchados de sangre de las FARC, dineros producto del narcotráfico, extorsión, secuestro, robos, desplazamientos, asesinatos, reclutamientos de menores, crímenes de guerra. ¿Y tú quieres absolverlos o es que tú eres dios o es que tú hablas por todos los colombianos? Maricón (JLTM) [2] Así Semana no lo publique, pero por lo menos a ellos les llega el mensaje: este Samper sí es un perro h.p. (Sensatus)

18 La investigación se basó en los comentarios de los lectores a columnas de Fernando Londoño, Alfredo Molano, Antonio Caballero, María Jimena Duzán, y de los dos autores cuyas columnas analizamos aquí: Daniel Coronell y Daniel Samper Ospina, entre septiembre y noviembre de 2008. 
Aquí el uso del disfemismo configura la afrenta; el autor del comentario [1] encuentra en él la peroratio perfecta para cerrar sus argumentos, mientras que el [2] lo revela también como cierre, luego de haber preparado el terreno con cierto aire de preterición. Situación similar presenta el 13\% de los comentarios revisados sobre el texto irónico, en contraste con un escaso 3\% para el texto no irónico, tal como se revela en la tabla siguiente:



Gráfico 5. Resultados en cuanto a insultos hacia el autor.

Si concebimos el insulto como reacción pasional primaria, una vez más tendríamos que traer a colación el tema de la actitud afectiva que, según Yus (2016), mueve los hilos de las interacciones verbales en los complejos campos del humor y la ironía. De nuevo, el lector barrunta en el texto las actitudes disociativas y los ecos con los que el autor construye toda una arquitectura textual de la ironía, solo que esta vez todo el aparataje de evaluaciones, ataques y diversión van en la dirección contraria de sus preferencias políticas y tocan al líder de sus afectos, por lo cual la reacción, casi reptílica, no da espera y explota con el insulto. En este caso, lo que Yus considera como sesgo normativo de la ironía (normative bias of irony) juega en contra del lector: "this bias refers to the fact that the most common use of irony is to criticise or complain (via dissociative attitude) about a situation, event, opinion, norm, etc. that is echoed and did not live up to the expectation" (2016: 223). Esto justifica las reacciones airadas que se valen de la función exorcística que les brinda el disfemismo, con el fin de responder a la provocación actitudinal disociativa, ecoica y sesgada de la ironía.

\subsection{El vendaval de descalificaciones al texto}

En la misma línea de reacciones explosivas, nos ocuparemos, por último, de una categoría casi exclusiva de los comentarios a la columna irónica: la descalificación de su calidad como texto. Este es el panorama que arroja la revisión:



Gráfico 6. Resultados en cuanto a descalificaciones al texto. 
El hallazgo resulta un tanto sorpresivo, pues se podían esperar los rechazos, las falacias o, incluso, los insultos, pero no la reprobación a la construcción misma del texto, tal como se advierte en los siguientes comentarios:

- Vaya estupidez, periodista maluco (AF)

- Parce, retírese, usted es realmente pésimo (Percanta20)

- Me dormí en el segundo párrafo (LL)

- Señor Daniel Samper Ospina, con todo el respeto que usted se merece, qué mal artículo, soy lector de sus columnas pero esta deja ver el poco esfuerzo que hace para ganarse la platica. Su columna parece la columna de cortar y pegar, y no entiendo una revista tan seria como Semana permite que un columnista haga este tipo de trabajos. Se nota que esto no pasa por ningún tipo de filtros para revisar los errores. Qué lástima porque una columna en una revista de tanto prestigio no se utiliza para un absurdo de estos (Vigilado)

- Daniel: Estudie hermano, para que pueda escudriñar la realidad colombiana y opinar sobre ella. Deje ya sus sainetes estúpidos (MAVQ)

- Señor, madure, qué bobadas, ahora entiendo el porqué del desencanto de la gente con Semana. Como era de buena (LE)

- Qué bobadas. Ya es hora de que madure, chino. No se sabe quién dice más pendejadas, si su tío o usted (Danapack)

Aunque este fenómeno podría atraer otros análisis ${ }^{19}$, al menos una conjetura quisiéramos incluir en procura de una explicación a tal reacción. Se trata de la posible ruptura del horizonte de expectativas del lector ante el texto irónico presentado. El hecho de que, en la sección de opinión de una revista, en lugar de un texto argumentativo canónico, aparezca un diálogo ni siquiera real (que rompe, de suyo, con la facticidad esperada) puede generar desencanto en quienes esperan un "artículo serio"20. Seguramente, la arquitectura de la ironía que carnavaliza los niveles de la infraestructura (gracias al travestimiento de géneros), la textualización (mediante la inversión de principios y máximas conversacionales) y la responsabilidad enunciativa (a través de la inserción de enunciadores absurdos) provoca en muchos lectores cierto choque con lo que esperan de entrada, algo que no ocurrió con el texto de Daniel Coronell, inscrito por completo en la arquitectura canónica de la columna de opinión. Sin duda, esta exposición se paga perlocutivamente en términos del autor («periodista maluco», «parce, retírese», «madure, chino»), de la columna («me dormí en el segundo párrafo», «columna de cortar y pegar» y del género mismo («deje ya sus sainetes estúpidos»). Todo esto entraña el riesgo discursivo de la ironía, del que hablaba Jankélévitch:

19 Por ejemplo, la recurrencia de marcas textuales en torno a la ironía como inmadurez podría iluminar un análisis sobre representaciones sociales de la ironía en la cultura colombiana, apoyado en trabajos como los de Pardo-Abril (1999 y 2005).

20 Entrecomillamos el término, en atención a las consideraciones de Ruiz-Gurillo sobre géneros serios y géneros humorísticos; al respecto declara que "por lo que afecta a los géneros serios, estos pueden integrar el humor, de manera que cabría establecer una diferenciación entre géneros humorísticos y géneros serios a la hora de abordar el humor" (2012: 43-44). Sabemos que, en un principio, el género de la columna de opinión se inscribe entre los géneros serios; sin embargo, en el caso de Samper-Ospina asistimos a la transformación y nacimiento de un nuevo género humorístico, gracias a la carnavalización de su arquitectura, a la ironía continuada y al ethos discursivo que logra el autor, en virtud de la publicación semanal ininterrumpida de textos de este tipo. 
La ironía, que ya no le teme a las sorpresas, juega con el peligro. En este caso, el peligro está en una jaula: la ironía va a verlo, lo imita, lo provoca, lo ridiculiza, lo mantiene para su recreación; incluso se arriesgará a través de los barrotes para hacer la diversión tan peligrosa como sea posible, para obtener la ilusión completa de la verdad. Saca partido de su miedo fingido y no se cansa de salvar ese peligro delicioso que muere a cada instante. A decir verdad, la maniobra puede descarriarse, y por eso murió Sócrates” (2012: 12).

Esta muerte no solo ocurre en el plano de lo real (como tristemente acaeció en 1999 con el periodista colombiano Jaime Garzón), sino también en lo discursivo, tal como lo evidencian las descalificaciones, las falacias y los insultos de los que nos hemos ocupado en estas últimas categorías.

\section{CONCLUSIÓN}

En el intento de comparar los comentarios al texto no irónico -La criminalización del que investiga de Daniel Coronell- con los del texto irónico - iSe me van a la guerra, hijitos! de Daniel Samper Ospina- hemos visto que, a pesar del número mayor de comentarios que suscitó el primero, estos se pueden agrupar, de manera más o menos simple, en torno a las categorías de adhesión y rechazo, ya que los lectores sientan su posición, en buena medida, sobre la discusión de las premisas que ha presentado el autor, así se ayuden para ello de un buen número de argumentos extratextuales, provenientes de sus conocimientos previos o de sus convicciones políticas. En cambio, si revisamos los argumentos que esgrimen los lectores acerca del texto irónico, la clasificación se complejiza, ya que despuntan otras categorías de análisis, como el incremento de posturas indefinidas, el elevado porcentaje de argumentos no pertinentes, la respuesta desmesurada a la provocación del título, la afluencia de elogios directos o, en el polo opuesto, las falacias, los insultos y las descalificaciones al texto.

Todo esto nos suscita, al menos, cuatro ideas-fuerza; la primera, en cuanto al estado del arte; la segunda, sobre el modelo de comprensión elegido; la tercera, sobre la pluralidad del auditorio; y la cuarta, sobre la respuesta emocional de los lectores.

a. En cuanto a investigaciones precedentes, vislumbramos importantes puntos de contacto. Por ejemplo, con Magdaleno y Gutiérrez-Rivas, coincidimos en que estos espacios virtuales de participación trascienden los propósitos para los que fueron creados y dejan aflorar todo tipo de actos de habla; en efecto, los investigadores aseveran que allí "se emiten enunciados directivos cuyo significado implícito, o no literal, no simplemente se limita a la petición, sino que cumple funciones pragmáticas distintas (por ejemplo: ironía, admiración, rechazo, entre otras)" (2013: 20). De otro lado, reconocemos en el trabajo de Martínez-Egido (2014) una importante pista para explicar los ataques al autor y, sobre todo, las descalificaciones a su texto, en virtud de la ruptura de expectativas que provoca la presencia de elementos humorísticos e irónicos ${ }^{21}$; ya él lo advertía en las columnas de opinión que analizaba (así no fueran

21 Aunque este tema daría para otro artículo, vale la pena aclarar que, en cuanto a las diferencias entre humor e ironía, nos adscribimos a la posición de Ruiz-Gurillo, según la cual estos fenómenos, aunque cercanos, resultan diferentes: "El humor puede emplear entre sus recursos la ironía. La ironía, por su parte, puede ser humorística o 
de ironía continuada como las de Samper-Ospina): "el lector no espera que aparezca este rasgo en el discurso porque la temática social no parece prestarse a ello" (2014: 123). Sin embargo, reconocemos que aún es necesaria más investigación sobre las reacciones del lector a la ironía para responder a asuntos cruciales como los que proponen Eisterhold, Attardo y Boxer (2004), en términos de si los comentarios de los lectores responden a lo dicho o a lo implicado, o si solo se quedan en la risa o en el silencio (2004: 1242). Otro frente de análisis -aquí descartado desde la depuración del corpus- es el de los usos de la ironía en las interacciones entre lectores, alrededor de este texto; allí se podría dialogar con las conclusiones del estudio de Pano-Alamán (2013) para saber en qué medida cuando se opina en la Red, la ironía se manifiesta "a través del desdoblamiento de voces en el discurso o por medio de la mención, entendida aquí como procedimiento de cita directa o indirecta del discurso ajeno" (2013: 209).

b. Apoyados en el modelo constructivo-integrativo que elegimos para avistar el fenómeno de la comprensión de lectura tras estos comentarios, podríamos afirmar que un buen número de los lectores pasaron por alto la intención irónica del autor y tropezaron en la construcción del texto base, por lo que se adhirieron, más bien, a algún detalle del código de superficie y juzgaron, a priori, desde el marco situacional, amparados en sus conocimientos previos y en los preconstructos de sus propias filiaciones políticas. En este sentido, podríamos aferrarnos a la hipótesis de Nielsen, según la cual, los usuarios de la Red no leen; solo pasan su vista por los tags, en aquello que Cassany, Luna y Sanz (2003) han denominado como lectura en skimming.

c. En respuesta a la pluralidad de opiniones, salta a la vista la diversidad de lectores, lo que nos lleva a recordar el concepto de poliacroasis que Albaladejo (1998-1999, 2000, 2001, 2009) propone como correlato de la polifonía. La poliacroasis, "consistente en la diversidad de los oyentes del discurso retórico, los cuales constituyen un auditorio plural, un conjunto de oyentes diversos que llevan a cabo múltiples y diferentes actos de audición/interpretación del discurso" (Albaladejo 1998-1999: 12), cobra una riqueza inusitada al contacto con un texto de ironía continuada, tal como lo demuestran las categorías aquí explicadas. Si concebimos la ironía como prisma, como detonadora de sentidos, como dispositivo polifónico per se, también debemos descifrar, al otro lado de ella -y más para el género de la columna en el medio virtual-, sus efectos entre un auditorio plural que la interpreta de modos diversos e impredecibles. Si bien la investigación sobre la ironía ya cuenta con la polifonía como rasgo distintivo (Ducrot 1988; Bruzos-Moro 2005 y 2009), es hora de ocuparnos también de sus múltiples impactos entre las comunidades discursivas; es hora de atender, desde la perspectiva de Albaladejo, a la poliacroasis de la ironía.

d. Si nos ubicamos en el marco de las tres finalidades del discurso que nos vienen desde Quintiliano -docere, delectare y movere ${ }^{22}$ - resulta evidente que el territorio

no. Hay humor sin ironía y hay ironía sin humor" (2012: 131). En el caso de los textos de Daniel Samper -más que humor- hallamos ironía, en virtud de las funciones evaluativas y de ataque verbal que antes anotábamos, desde los postulados de Alba-Juez (2002), y que se suman a la de simple diversión.

22 Afirma Marimón-Llorca: "Quintilian (Institutio Oratoria 12, 10, 59) explains how the speaker -after having assessed the characteristics of the cause to be defended- will have to choose the discursive means that will allow him to persuade a specific audience, it is the ad persuadendum accomodate dicere, the basis and principle of rhe- 
privilegiado por el texto irónico de Samper Ospina ha sido el del movere, aquel que, según Marimón-Llorca, "desencadena una conmoción afectiva” (2016: 76). Del amor al odio, del elogio al insulto, del aplauso a la descalificación, la respuesta de los lectores transita, en efecto, por la línea del pathos; más aún, dadas las comparaciones con los comentarios al texto no irónico y echando mano de la metáfora por la que apostamos en el título, podríamos hablar de una tormenta patética, de un aluvión pasional, de una respuesta exacerbada a la provocación de la ironía. Así no se lea completo, así solo se mire el título, así no se comprenda siquiera, el texto irónico ha despertado pasiones entre los usuarios de la Red; en última instancia, ha desatado las lenguas, como lo postula Jankélévitch en la cita que adoptamos por epígrafe. Sin duda, todo este análisis en torno a los efectos de la ironía ha quedado signado por el concepto de actitud afectiva que ha trazado Yus (2016) y que mueve los hilos de las actitudes disociativas y de los ecos detrás de esta arquitectura carnavalesca; no en vano, Kočman habla de que "la principal función de la ironía es que el hablante exprese una actitud o evaluación del material al que alude" (2011: 389). Ahora bien, esa misma actitud afectiva que determina el proceder textual del autor, vive en las respuestas perlocutivas del lector, latente en las alabanzas, las falacias, los improperios y las desaprobaciones. La ironía, en suma, le toma el pulso al pathos del lector, pone a prueba sus emociones más primarias.

A la luz de estas consideraciones, sentimos, a pesar de todos los otros frentes que soslayamos, que este trabajo se conecta con los diversos estudios sobre la complejidad pragmalingüística (Grupo GRIALE), enunciativa (Ducrot), retórica (Booth, Schoentjes), política (Hutcheon) y epistémica (Jankélévitch) del fenómeno irónico, lo que abre las puertas a nuevos proyectos que exploren el panorama variopinto de los efectos perlocutivos de la ironía en el receptor: los finos aleteos sociodiscursivos que, al estilo de un efecto mariposa, desencadenan una tormenta patética al otro lado del texto.

\section{Referencias bibliográficas}

Alba-Juez, L. (2002). Análisis de las funciones y estrategias del discurso irónico [Tesis doctoral]. Universidad Complutense de Madrid: http://eprints.ucm.es/3383/

Albaladejo, T. (1989). Retórica. Madrid: Síntesis.

Albaladejo, T. (1998-1999): "La poliacroasis como componente de la comunicación retórica". Tropelias: Revista de teoría de la literatura y literatura comparada, 9-10, pp. 5-20.

Albaladejo, T. (2000): "Polifonía y poliacroasis en la oratoria política: propuestas para una retórica bajtiniana”. En F. Cortés, G. Hinojo y A. López (eds.), Retórica, Política e Ideología. Desde la Antigüedad hasta nuestros días. Actas del II Congreso Internacional de LOGO, Asociación Española de Estudios sobre Lengua, Pensamiento y Cultura Clásica. Salamanca: Logo, pp. 11-21. Albaladejo, T. (2001): "Retórica, tecnologías, receptores". Revista de Retórica y Teoría de la Comunicación, 1, pp. 9-18.

torical discourse. The first step to achieve this aim consists in establishing the right persuasion degree or intensity for the issue in question and choosing how to draw the path of persuasion: appealing to the intellect (through the docere), trying to arouse the audience's sympathy (by means of the delectare) or triggering an affective commotion (the movere)" (2016: 76). 
Albaladejo, T. (2009): "La poliacroasis en la representación literaria: un componente de la retórica cultural”. Castilla: Estudios de literatura, 0, pp. 1-26.

Alvarado-Ortega, B. y Ruiz-Gurillo, L. (coords.) (2013). Humor, ironía y géneros textuales. Universidad de Alicante.

Aristóteles (1964). Obras (Trad. F. Samaranch). Madrid: Aguilar

Arrieta, M. (2013). "La ironía como recurso y estilo argumentativo: Una evaluación diagnóstica de la comprensión textual”. En Lectura y escritura: Debates y desafios para el mejoramiento de la calidad educativa. Cartagena: VI Congreso Nacional de la Cátedra Unesco, pp. 624-644

Bajtín, M. (1976). "Carnaval y Literatura”. Revista Eco, 134, pp. 311-338.

Booth, W. (1986). Retórica de la ironía. Madrid: Taurus.

Bordes-Solana, M. (2011). Las trampas de Circe: Falacias lógicas y argumentación informal. Madrid: Cátedra.

Bronckart, J. P. (2004). Actividad verbal, textos y discursos: Por un interaccionismo socio-discursivo. Madrid: Fundación Infancia y Aprendizaje.

Bruzos-Moro, A. (2005). "Análisis de la enunciación irónica: Del tropo a la polifonía". Pragmalingüística, 13, pp. 25-49.

Bruzos-Moro, A. (2009). "La polifonía”. En L. Ruiz-Gurillo y X. Padilla-García (eds.), Dime cómo ironizas y te diré quién eres (45-64). Universidad de Alicante: Peter Lang.

Camargo, Z.; Uribe, G.; y Caro, M. A. (2011). Didáctica de la comprensión y producción de textos académicos. Armenia: Universidad del Quindío.

Caro, M. A. y Castrillón, C. A. (2011). Burlemas e infortunios en la ironía de Les Luthiers. Universidad Tecnológica de Pereira.

Cassany, D.; Luna, M.; y Sanz, G. (2003). Enseñar lengua. Barcelona: Graó.

Cortés-Martínez, C. A. (2010). La argumentación en las columnas de opinión: Cómo argumentan los columnistas en la era Uribe [Trabajo de grado en Comunicación Social]. Pontificia Universidad Javeriana: https://repository.javeriana.edu.co/handle/10554/5411

Crespo-Lajara, V. (2008). Las claves argumentativas de la ironia: Una aproximación argumentativa al fenómeno irónico [Informe para el Diploma de Estudios Avanzados]. Universidad de Alicante

Dijk, T. (1978). La ciencia del texto. Un enfoque interdisciplinario. Barcelona: Paidós.

Dijk, T. y Kintsch, W. (1978). "Towards a model of discourse comprehension and production". Psychological Review, 85, pp. 363-394.

Dijk, T. y Kintsch, W. (1983). Strategies of Discourse Comprehension. NY: Academic Press.

Ducrot, O. (1988). Polifonía y argumentación. Conferencias del seminario Teoría de la Argumentación y Análisis del Discurso. Cali: Universidad del Valle.

Eisterhold, J.; Attardo, S.; y Boxer, D. (2006). "Reactions to irony in discourse: evidence for the least disruption principle". Journal of Pragmatics, 38, pp. 1239-1256. DOI: 10.1016/j.pragma.2004.12.003

Hutcheon, L. (2003). "Política de la ironía". En P. Schoentjes, La poética de la ironía. Madrid: Cátedra, 241-250.

Jankélévitch, V. (2012). La ironía. México: Editorial Me cayó el veinte.

Kintsch, W. (1998). Comprehension. A paradigm for cognition. Cambridge: University Press.

Kočman, A. (2011). La ironía verbal como semejanza incongruente [Tesis doctoral]. Universidad de Salamanca: https://gredos.usal.es/jspui/bitstream/10366/110705/1/DLE_Kocman_A_LaIronia.pdf

Magdaleno, N. y Gutiérrez-Rivas, C. (2013). "Funciones pragmáticas de la petición en los comentarios del público a una noticia periodística virtual". Íkala, revista de lenguaje y cultura, Universidad de Antioquia, 18, pp. 19-33.

Marimón-Llorca, C. (2016). "Rhetorical strategies in discourses about language: the persuasive resources of ethos". Rhetoric in Spain, 1, pp. 68-89.

Martínez-Egido, J. J. (2014). "El humor en el artículo de opinión". Feminismo/s, Universidad de Alicante, 24, pp. 117-141. 
Martínez-Miguélez, M. (2004). Ciencia y arte en la metodología cualitativa. México: Trillas.

Moreno-Fernández, F. (1990). Metodología sociolingüística. Madrid: Gredos.

Nielsen, J. (2000). Usabilidad: Diseño de sitios Web. Madrid: Pearson Educación.

Pano-Alamán, A. (2013). "La ironía, entre polifonía y mención ecoica. Cuando se opina en la Red". En B. Alvarado-Ortega y L. Ruiz-Gurillo (coords.), Humor, ironía y géneros textuales. Universidad de Alicante, pp. 191-212.

Pardo-Abril, N. (1999). "Análisis crítico del discurso: un acercamiento a las representaciones sociales”. Forma y función, Universidad Nacional de Colombia, 12, pp. 63-81.

Pardo-Abril, N. (2005). Ideología, representaciones sociales, modelos culturales y modelos mentales: http://www.unal.edu.co/ieco/images/stories/docs/ideologiamodelosculturales.pdf

Rodríguez-Rosique, S. (2009). "Una propuesta neogriceana”. En L. Ruiz-Gurillo y X. Padilla-García (eds.), Dime cómo ironizas y te diré quién eres. Universidad de Alicante: Peter Lang, pp. 109-132.

Ruiz-Gurillo, L.; Marimón-Llorca, C.; Padilla-García, X. y Timofeeva, L. (2004). "El proyecto GRIALE para la ironía en español: conceptos previos". Estudios de Lingüistica Universidad de Alicante, 18, pp. 231-242.

Ruiz-Gurillo, L. y Padilla-García, X. (eds.) (2009). Dime cómo ironizas y te diré quién eres. Universidad de Alicante: Peter Lang.

Ruiz-Gurillo, L. (2012). La lingüistica del humor en español. Madrid: Arco/Libros.

Schoentjes, P. (2003). La poética de la ironía. Madrid: Cátedra.

Torres-Hernández, N. y Velandia-Pedraza, Z. (2008). "De la antigua a la nueva retórica". Cuadernos de Lingüística Hispánica, Universidad Pedagógica y Tecnológica de Colombia, 11, pp. 119-130.

Vega-Reñón, L. (2007). Si de argumentar se trata. Madrid: Montesinos.

Yus, F. (2016). Humour and Relevance. Amsterdam: John Benjamins. 